fournal of Medical Genetics (1973). 10, 8.

\title{
Electromyographic Studies in Parents of Children with Spinal Muscular Atrophy
}

\author{
A. E. H. EMERY,* A. R. ANDERSON,* and M. J. NORONHA
}

\begin{abstract}
Summary. Electromyographic studies have been carried out on the quadriceps and deltoid muscles of a number of healthy parents of children with infantile spinal muscular atrophy (types I and II) and the results compared with those obtained in healthy controls of the same sex. The results indicated an increase in mean amplitude of action potentials in quadriceps and deltoid muscles in both fathers and mothers (statistically significant in the quadriceps in the latter) of children with type I spinal muscular atrophy (Werdnig-Hoffmann disease). Increase in the mean amplitude in the quadriceps and deltoid muscles in mothers of children with type II spinal muscular atrophy and the mean duration of action potentials in the quadriceps muscle in mothers of children with type I and type II spinal muscular atrophy were also observed, but the differences from controls were not significant.
\end{abstract}

The spinal muscular atrophies (SMA) may be defined as a group of inherited diseases in which there is degeneration of the anterior horn cells (lower motor neurones) of the spinal cord and often the bulbar motor nuclei, but with no evidence of pyramidal tract involvement. On clinical and genetic grounds it has been suggested that there are some 20 different forms of SMA (Emery, 1971). The commonest and most severe form presents as progressive muscle weakness, mainly affecting the proximal limb musculature, beginning in the first year of life (usually before 3 months of age) and terminating in death before the age of 4 (usually before the age of 2). This is referred to as WerdnigHoffmann or type I SMA and is inherited as an autosomal recessive trait. It has been suggested that there may be another form of proximal SMA somewhat similar to type I with onset between 3 and 15 months and survival beyond 4 years, usually into adolescence or later (Fried and Emery, 1971). This has been referred to as type II SMA and may also be inherited as an autosomal recessive trait.

No specific biochemical abnormality has yet been identified in any of the SMAs. Apart from abnormal muscle histology the most important laboratory

\footnotetext{
Received 26 September 1972.

* From the University Department of Human Genetics, Western General Hospital, Edinburgh.

† From the Department of Neurology, Booth Hall Hospital, Manchester.
}

finding in SMA is electromyographic (EMG) evidence of anterior horn cell degeneration with loss of corresponding motor units. Such EMG abnormalities include spontaneous regular motor unit activity (fibrillation and fasciculation potentials) and on voluntary contraction of the muscle reduced interference pattern, 'giant' action potentials (high amplitude and long duration) and the mean action potential duration and amplitude is generally increased (Lambert, 1963; Gardner-Medwin, Hudgson, and Walton, 1967; Hausmanowa-Petrusewicz et al, 1968; Meadows, Marsden, and Harriman, 1969a and b; Buchthal and Olsen, 1970). In the present investigation the EMG of parents of children with types I and II SMA was studied in the hope that the technique might prove a means of detecting heterozygotes and thereby help resolve the genetics of these disorders.

\section{Materials and Methods}

All the parents were healthy with no muscle weakness and all had at least one child affected with type I or II SMA. Healthy individuals with no history of any neuromuscular disorder and of comparable age to the parents were used as controls. Recordings were obtained during minimal voluntary contraction usually from both the deltoid and quadriceps muscles but in a few individuals recordings were made from only one of these muscle groups. The ambient temperature was usually about $21^{\circ} \mathrm{C}$. 
The equipment used was a Medelec MS4 portable electromyograph. Concentric needle electrodes (E/NS 1) were used with a core diameter of $0.122 \mathrm{~mm}$. Action potentials were recorded using a fibre optic recorder on Kodak Linagraph direct print paper. Each region of film recorded from one particular site was enlarged and tracings made of individual action potentials which were then measured. Usually at least 20 different action potentials were studied in each individual. Any evidence of spontaneous activity was also noted. All records from both parents and controls were analysed without knowledge as to the identity of the subject.

For each individual the mean potential duration and mean amplitude were determined and the mean of these individual mean values was then determined for all controls and all parents. The significance of the difference between the mean values for the controls and parents was assessed by Students $t$ test.

\section{Results}

In none of the controls or parents was there any evidence of spontaneous activity (fibrillation or fasciculation potentials).

With regard to the results in the controls, because of differences in the duration and amplitude of action potentials in quadriceps and deltoid muscles and in males compared with females for the same muscle (Table I), results for quadriceps and deltoid muscles and for males and females are considered separately. In the age ranges studied there was no significant regression on age for mean duration or mean amplitude for either quadriceps or deltoid muscles in males (age range 21 to 42 ) or females (age range 25 to 47 ). There was also no significant regression on weight for mean duration or mean amplitude for either muscle in males or females.

The results (Table I) indicate that compared with the mean values for the controls the mean amplitude was greater in quadriceps and deltoid muscles in both fathers and mothers of type I SMA, but only in mothers of type II SMA. In the case of mothers of type I SMA the difference from controls for the quadriceps muscle was significant $(p<0.05)$, and two out of six of these mothers had values outside the normal range. However, included in the controls was one female with a spuriously high value (compared with the other controls) and if this value is discounted then five out of six of the mothers of type I SMA had mean amplitudes outside the normal range for the quadriceps muscle. The control with a spuriously high value might herself be a carrier. The likelihood of this is difficult to estimate, however, since there are as yet no accurate figures for the incidences of any of the different forms of SMA.

Compared with the mean values for the controls, the mean durations were greater in the quadriceps muscle in mothers of both type I and type II SMA, but the differences were small and not statistically significant.

The proportion of action potentials with more than four phases (polyphasic) varied considerably between individual controls and parents, and since the number of parents studied was small it was not possible to draw any meaningful conclusions regarding differences in the proportion of polyphasics in controls and parents.

\section{Discussion}

The aim of the present study was to investigate the possibility of detecting electromyographic abnormalities in parents of children with infantile SMA. Previously there appears to have been only one published report of EMG studies in unaffected relatives in a family with SMA (Spira, 1967). In the family reported there were three males affected with the relatively benign Kugelberg-Welander or type III form of proximal SMA, apparently inherited as an autosomal recessive trait. EMG abnormalities

TABLE I

AMPLITUDE AND DURATION (MEAN + SD) OF ACTION POTENTIALS IN CONTROLS AND PARENTS OF CHILDREN WITH TYPES I AND II SMA

\begin{tabular}{|c|c|c|c|c|c|c|}
\hline & \multicolumn{3}{|c|}{ Quadriceps } & \multicolumn{3}{|c|}{ Deltoid } \\
\hline & $\begin{array}{c}\text { No. of } \\
\text { Individuals }\end{array}$ & $\underset{(\mu \mathbf{V})}{\text { Amplitude }}$ & $\underset{\text { (msec) }}{\text { Duration }}$ & $\begin{array}{c}\text { No. of } \\
\text { Individuals }\end{array}$ & $\underset{(\mu \mathrm{V})}{\text { Amplitude }}$ & $\underset{\text { (msec) }}{\text { Duration }}$ \\
\hline $\begin{array}{l}\text { Males } \\
\text { Controls } \\
\text { Fathers (type I) } \\
\text { Fathers (type I ) }\end{array}$ & $\begin{array}{r}15 \\
7 \\
6\end{array}$ & $\begin{array}{l}383 \cdot 8 \pm 98 \cdot 6 \\
405 \cdot 5 \pm 101 \cdot 6 \\
335 \cdot 2 \pm 30 \cdot 0\end{array}$ & $\begin{array}{l}8 \cdot 3 \pm 1 \cdot 2 \\
7 \cdot 5 \pm 1 \cdot 3 \\
8 \cdot 4 \pm 1 \cdot 6\end{array}$ & $\begin{array}{r}12 \\
7 \\
8\end{array}$ & $\begin{array}{l}317 \cdot 8 \pm 58 \cdot 4 \\
321 \cdot 3 \pm 83 \cdot 5 \\
315 \cdot 8 \pm 59 \cdot 6\end{array}$ & $\begin{array}{l}8 \cdot 4 \pm 0.8 \\
7 \cdot 8 \pm 1 \cdot 5 \\
7 \cdot 9 \pm 1 \cdot 6\end{array}$ \\
\hline $\begin{array}{l}\text { Females } \\
\text { Controls } \\
\text { Mothers (type I) } \\
\text { Mothers (type II) }\end{array}$ & $\begin{array}{r}17 \\
6 \\
11\end{array}$ & $\begin{array}{l}331 \cdot 5 \pm 61 \cdot 0 \\
423 \cdot 1 \pm 100 \cdot 9 * \\
349 \cdot 7 \pm 51 \cdot 1\end{array}$ & $\begin{array}{l}7 \cdot 2 \pm 1 \cdot 1 \\
8 \cdot 0 \pm 1 \cdot 2 \\
8 \cdot 4 \pm 1 \cdot 2\end{array}$ & $\begin{array}{r}11 \\
7 \\
11\end{array}$ & $\begin{array}{l}273 \cdot 7 \pm 37 \cdot 1 \\
311 \cdot 0 \pm 76 \cdot 3 \\
286 \cdot 4 \pm 41 \cdot 9\end{array}$ & $\begin{array}{l}8 \cdot 6 \pm 0 \cdot 9 \\
7 \cdot 7 \pm 1 \cdot 1 \\
8 \cdot 0 \pm 1 \cdot 6\end{array}$ \\
\hline
\end{tabular}

* Significant difference from controls, $\mathrm{p}<0.05$ 
were detected in two healthy individuals in the family one of whom, according to the pedigree, would be an obligate heterozygote. These abnormalities consisted of spontaneous fasciculations and long-duration, high amplitude potentials in the quadriceps muscle.

In the present study a significant increase in amplitude of action potentials recorded from the quadriceps muscle was observed in mothers of children (of both sexes) with type I SMA. There was overlap in the values from mothers and controls; nevertheless at least two out of six mothers of children with type I SMA had values right outside the normal range. On the other hand all of the values in 11 mothers of children with type II SMA lay well within the normal range. These preliminary findings perhaps add credence to the suggestion that types I and II SMA are separate entities. However study of a greater number of such parents would be necessary to clarify the situation.

The willing cooperation of parents and controls who volunteered for this study is gratefully acknowledged as is the assistance of Dr Rosalind Skinner with the electromyographic studies and Mrs Enid Clack in tracing families. This work was supported by generous financial assistance from the Garner Fund ( $\mathrm{Mr}$ and $\mathrm{Mrs}$ G. Garner) and the Muscular Dystrophy Group of Great Britain. The equipment was kindly provided by the Smith Kline and French Foundation.

\section{REFBRENCES}

Buchthal, F. and Olsen, P. Z. (1970). Electromyography and muscle biopsy in infantile spinal muscular atrophy. Brain, 93, 15-30.

Emery, A. E. H. (1971). The nosology of the spinal muscular atrophies. Fournal of Medical Genetics, 8, 481-495.

Fried, K. and Emery, A. E. H. (1971). Spinal muscular atrophy type II. Clinical Genetics, 2, 203-209.

Gardner-Medwin, D., Hudgson, P., and Walton, J. N. (1967). Benign spinal muscular atrophy arising in childhood and adolescence. Fournal of the Neurological Sciences, 5, 121-158.

Hausmanowa-Petrusewicz, I., Askanas, W., Badurska, B., Emeryk, B., Fidziańska, A., Garbalińska, W., Hetnarska, L., Jedrzejowska, H., Kamieniecka, Z., Niebrój-Dobosz, I., Prot, J., and Sawicka, E. (1968). Infantile and juvenile spinal muscular atrophy. Fournal of the Neurological Sciences, 6, 269-287.

Lambert, E. H. (1963). Electromyography and electric stimulation of peripheral nerves and muscles. In Clinical Examinations in Neurology, Mayo Clinic, 2nd edition, pp. 311-341. Saunders, London and Philadelphia.

Meadows, J. C., Marsden, C. D., and Harriman, D. G. F. (1969a). Chronic spinal muscular atrophy in adults. Part 1 . The Kugelberg-Welander syndrome. fournal of the Neurological Sciences, 9 , 527-550.

Meadows, J. C., Marsden, C. D., and Harriman, D. G. F. (1969b). Chronic spinal muscular atrophy in adults. Part 2. Other forms. Fournal of the Neurological Sciences, 9, 551-566.

Spira, R. (1967). A family with Kugelberg-Welander disease; electromyographic findings in sub-clinical cases. Confinia Neurologica, 28, 423-431. 